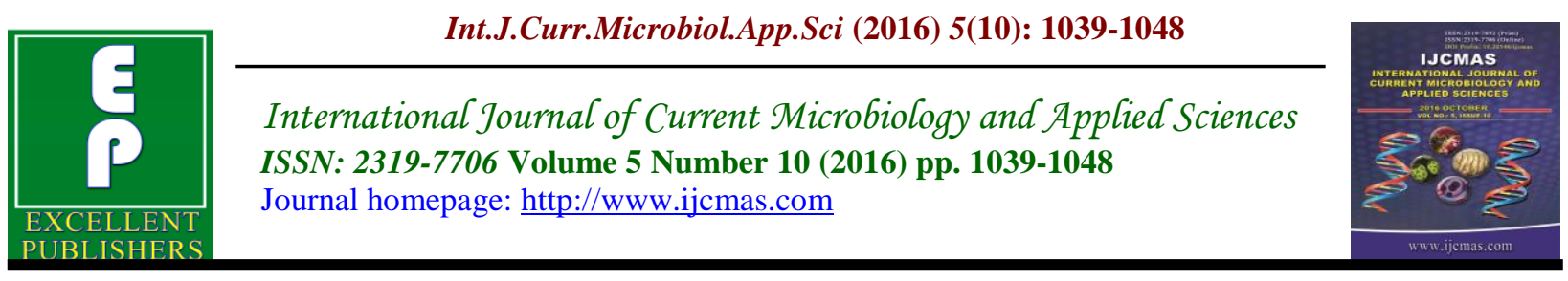

Original Research Article

http://dx.doi.org/10.20546/ijcmas.2016.510.110

\title{
Soil and Landscape Changes in the Alpine Zone Basin of the Rivers Garachay-Velvelechay
}

\author{
J.A. Shabanov* and T.A. Kholina \\ Baku State University, Azerbaijan \\ *Corresponding author
}

\section{A B S T R A C T}

\section{Keywords}

Soil and Landscape

Changes,

Alpine Zone

Basin,

grazing causes.

\section{Article Info}

Accepted:

20 September 2016

Available Online:

10 October 2016
In the article we have studied the current state of the soil-landscape complexes of the alpine zone basin of the rivers Garachay-Velvelechay, analyzed the changes that have occurred over the past 50 years, and estimation has been given. It was revealed that unregulated grazing causes, first, a change in plant formations (cereals and cereal-legume plants are replaced by weeds), thinness, and then the destruction of vegetation, which in turn causes soil degradation. In general, the productivity of alpine meadows at the studied area has decreased by $29 \%$, subalpine meadows - by $18 \%$ and meadow steppes - by $16 \%$. As a result of erosion processes, sometimes passing into pasture digression, the physical and chemical and physical properties of soils have deteriorated.

\section{Introduction}

Landscape highland areas are characterized by high dynamism and high vulnerability, especially in soil and vegetation. This is due both to the natural environment (difficult terrain, low power fine-earth layer, a strong incline and water flows under heavy rains and melting snow), and anthropogenic influence (mainly grazing). Consequently, despite the relatively short time of anthropogenic actions (no more than 2-4 months per year) on large areas has been disrupted the natural balance of soillandscape complexes, and violation of grass cover causes the intense development of erosion processes, which can lead to complete loss of soil and the formation of badlands (Mamedov et al., 2009; Museibov,
2013). Numerous researches on the current state of landscapes of alpine and subalpine meadows, used mainly for summer pastures and hayfields are carried out currently.

Gunya studied (Gunya, 2010) studied natural and natural-anthropogenic changes in the mountainous areas based on field research in the different mountain regions of the world.

While studying different ways of using natural pastures Torehanov and K.Sh. Smailov (Gunya et al., 2005) found that the use of feedlot method with separation the herbage up to $65 \%$ in the pasture rotation system optimizes the formation of the soil 
and increases the moisture content of the soil in the accumulation period. The increase in humus content and available phosphorus in the soil is observed, that provides a maximum forage production.

In his studies Usmanov (Usmanov, 2009) evaluated the degraded soils of the NorthWest Caspian on the effect of grazing loads on the productivity of plant communities and soil properties. Prediction of soil degradation and regulation of pasture loads studied also the researchers in Mongolia (Belozertseva et al., 2011).

Soil degradation while changing the use of land and the creation of new pastures in Sardinia studied Italian researchers (Zucca, 2010). Approaches to prevent land degradation and increase productivity of grasslands studied Rumanian soil scientists (Kohler et al., 2012).

Canadian researchers studied the compaction and trampling boreal pasture lands, as well as photomaps, comparing the effects of high and moderate pasture pressure (Willat et al., 1984).

The aim of our study was to examine the current state of the soil-landscape complexes of the alpine zone of the studied area, to identify the changes that have occurred over the past 50 years, and to evaluate them.

\section{Object and Methods}

River basins Garachay-Velvelechay are located in the north-eastern slope of the Greater Caucasus in Azerbaijan. The highland area is confined to the territory of the heights from 2000 to $4000 \mathrm{~m}$ above sea level. These include nival and subnival complex, developed on the high places, exceeding the snow line of the Greater Caucasus in the mountains - Garadagh,
Babadag, Garabulag, Kyalaydzha, Girdabat and alpine meadow complex represented by alpine and subalpine meadows, and on welldrained and relatively flat areas - meadow steppes. The area of the mountainous area and the basins of the rivers Garachai and Velvelichai covers 65684 hectares.

The climate in mountainous parts of river basins Garachay and Velvelechay is cold and the winter is dry. The average annual temperature at an altitude of $2000 \mathrm{~m}$ above sea level is $4,4^{0} \mathrm{C}$.

The relief is strongly dissected, steep of slopes is high - $20-25^{0}$, so under these circumstances erosion is widespread. Great influence on the development of erosion processes also has human activities, such as cattle grazing.

To study the soil and vegetation we have conducted field studies and analyzed literature sources and cartographic materials. Analyses of soil samples were carried out according to conventional techniques.

\section{Results and Discussion}

In the high part of the river basin GarachayVelvelechay are common nival and subnival landscape, alpine, subalpine meadows and meadow steppes.

Nival and subnival landscape developed on the rocky-crushed stone and rocky area is from $2-3$ to $20 \mathrm{~km}$. The total area of the landscape in the basin of the rivers Garachai-Velvelichai is 2100 hectares. On the rocky mountainous area snowfields can be seen. Intense physical weathering causes the formation of landslip materials. Under favorable conditions, they change into loose covers. In this belt small dusty particles of weathering products are involved in soil formation, promoting sparse vegetation. 
Nival and subnival zones of Azerbaijan were subjected to ancient glaciations that took place not only in the Quaternary period, but also in earlier geological epochs.

Rocky belt does not have directly agricultural value. However, its melt, glacial and spring waters feed the rivers, which in turn are used in irrigated agriculture. In addition, this zone is the habitat of mountain goats and tours.

The number of hours of sunshine per year in subnival belt is 1900 . The average annual air temperature is below 00; the average temperature in July is $5^{\circ} \mathrm{C}$, in January minus $14^{0} \mathrm{C}$. The amplitude of the annual temperature reaches $50^{\circ} \mathrm{C}$, resulting in intense physical weathering. The annual precipitation - 600-700 $\mathrm{mm}$, and in the warm half of the year -400 to $800 \mathrm{~mm}$, and in the cold season - 300-400 mm. In this zone during the year there are 3-7 days with hail, and 160 days with snow cover, which in some places reaches one meter height. Potential evaporation is $300 \mathrm{~mm}$, moisture 100-150\% (Shihlinsky, 1969).

After the retreat of the first phase of glaciers (16 thousand years ago) an alpine landscape began to mutate, began the formation of its individual components, which led to the development of sub-alpine meadows. Gradually, this process applies to most elevated parts of the alpine zone. This causes the development of the primitive land cover in this zone, especially on the southern slope.

In the rocky area vegetation is hardly developed. Vegetation is met only in some places and adapts to the harsh natural conditions. However, growing of even this meager vegetation is disturbed during the summer because of the taking cattle to alpine meadows; seminiferous stops and hampers gradual conversion of the rocky zone to the pasture. To accelerate the formation of vegetation it is advisable to sow the seeds of forage grasses.

It is regarded that the climate change will profoundly affect all components of mountain landscape and natural-economic relations. The most notable changes resulting from climate are observed in the nival-glacial landscapes of the north-eastern slope of the Greater Caucasus on the example of the general retreat of the glaciers. Retreat of glaciers led to the expansion of subnival lawns areas.

Alpine meadows are located between subnival landscape and sub-alpine meadows. This landscape covers 2863 hectares basin of the rivers Garachai-Velvelichai. Parts of the mountain meadows are rocky territory. The rough surface of the narrow watersheds with steep slopes complicates the use of alpine meadows as pastures and hayfields. More or less gentle slopes and high plateaus are used for grazing and hay.

The alpine zone of the studied area is characterized by folding of the rocks represented mainly by shale-sandstone strata and thick Cretaceous limestone.

In the alpine zone the meadow vegetation covers the individual areas, which are sometimes interrupted by rocky talus. Grasses and many kinds of herbs dominate in vegetation. Fescue dominates, but in some cases, common chamomile, fire, and mantle can be met. Oblique, partly steep and steep slopes are characterized by fire, bluegrass, cuff, stained mosses and lichens. The total amount of biomass in the alpine meadows is no more than 8,0-10,5 t/ ha.

The climate in alpine zone is very harsh. Cold period with frosty days is long, the 
growing season is short. In December and January persistent negative temperature ($\left.5,0-8,9^{0} \mathrm{C}\right)$ is observed. The absolute minimum of air temperature during the year is minus $22-26^{\circ} \mathrm{C}$. The average annual rainfall is $800-1200 \mathrm{~mm}$. The snow cover lasts 120-160 days. The average height of snow cover during the year is $40-50 \mathrm{~mm}$. In the alpine meadows the annual value of the radiation balance is $30-34 \mathrm{kcal} / \mathrm{cm} 2$, and the relative moisture - 65-75\%. Type of climate is cold, dry winter.

Typical soils of alpine meadows are mountain-meadow turf-peaty soils. They are confined mainly to the decrease or the bottoms of glacial cirques with seasonal surface moisture (Babayev et al., 2011).

The rich alpine vegetation with a well developed root system and promotes fescue formation and significant accumulation of organic residues. Humus is formed rough, like moder, and is associated with the duration of the cold period, and, accordingly, a short growing season, low microbial activity, which prevents complete decomposition of organic litter.

The most characteristic morphological features of mountain-meadow turf-peaty soils: the presence of a dense sod and weak turf, low power profile, the profile crushed stone increasing with depth. Carbonate formations are absent. Where there are the conditions for standing water (micro depressions, bottoms of glacial cirques), small signs of gley can be observed in the horizon B.

According to our analysis, the content of humus in the upper horizons of the mountain meadow turf-peaty soils of the studied area is quite high - from 5.96 to $6.58 \%$. Fulvic acids predominate in the humus. Accordingly, nitrogen content in the upper horizons is in average $0,32-0$, and $41 \%$. The exchange capacity ranges from 25 to 31 me/100 $\mathrm{g}$ soil. The reaction of the soil solution is mainly slightly acid $(5,6-6,2)$.

The content of physical clay $(<0.01 \mathrm{~mm})$ ranges from 29.48 to $35.32 \%$, and the content of clay particles is low - from 5.12 to $7.88 \%$. Mountain-meadow turf-peaty soils of the study area are light and medium loamy.

Reserves of humus in the layer $0-50 \mathrm{~cm}$ is $191 \mathrm{t} / \mathrm{ha}$, and the total nitrogen is $13.80 \mathrm{t} / \mathrm{ha}$, i.e., mountain-meadow turf-peaty soils have a high potential fertility. These soils have also a good water-physical properties.

Mountain-meadow turf-peaty soils together with other subtypes of mountain meadow soils are a major land reserve fodder lands of the republic and are mainly used for grazing. However, these soils are subject to erosion due to both natural factors (difficult terrain, low power fine-earth layer, a large number of scatterings, strong slope and water flow during heavy rains and melting snow) and anthropogenic (grazing). According to our data, in the basin of the rivers GarachaiVelvelechai these soils to some extent eroded: moderate developed erosion is on an area of 1404 hectares, to a lesser degree - in the area of 1459 hectares.

Unregulated grazing leads first to a change in plant formations (cereals and cereallegume plants are replaced by weeds), thinness, and then the destruction of vegetation, which in turn leads to soil degradation, the so-called pasture digression. Digression development depends on the specific features of grazed animals, intensity and duration of the use of pastures, endurance pasture vegetation to trampling. Violation for years a distant-pasture grazing regime of use, when much of the livestock 
remains on nearby pastures in the summer, causes in dry years a sharp increase of xerophytization of mountain steppes, a decrease of projecting cover, the development of erosion beds.

According to Hajiyev (1974), the biomass of the aerial part of the alpine meadows averaged $32 \mathrm{t} / \mathrm{ha}$. At the same time, the productivity of alpine meadows (aboveground biomass) is $22.8 \mathrm{q} / \mathrm{ha}$, i.e. decreased by almost a third $(29 \%)$. To raise the productivity of alpine meadows it is necessary to fight against soil erosion, as well as the use of mineral and organic fertilizers, and on disturbed areas artificial grass cultivation (mainly cereals.)

Sub-alpine meadows subalpine zone lies slightly above the upper boundary of the mountain forests. The upper limit of the zone in the alpine carpet reaches the 2200$2300 \mathrm{~m}$ height, and the lower part - along the forest glades, in areas of felled forests fall to $1700-1800 \mathrm{~m}$. Variety of subalpine meadows depends on topography, climate and slope exposure. This type of landscape in the study area occupies 38,590 hectares.

Soil-forming rocks are represented by acid and basic volcanic rocks - andesites, andesite-basalts, porphyries and eluvial products of weathering.

Type of climate in subalpine meadows is cold with dry winter. The subalpine meadows radiation balance is $35-40 \mathrm{kcal} /$ $\mathrm{cm}^{2}$, i.e., greater than about $10 \mathrm{kcal} / \mathrm{cm}^{2}$ than in the alpine meadows. The average annual temperature is $4,7-5,0^{\circ} \mathrm{C}$. The relative humidity is $65-75 \%$. In the warm half of the year 300-600 mm of rain falls. The sum of temperatures above $10^{\circ} \mathrm{C}$ is $800-2000^{\circ}$.

Vegetation in subalpine meadows is characterized by great diversity and is due to exposure of the slope and the degree of hydration. Vegetation is represented by cereals, grass, moderately wet subalpine meadows. Here dominates fescue, brome, alfalfa, foxtail, bluegrass, buttercup, savory. The total biomass of subalpine meadow vegetation within $285-349 \mathrm{~kg} / \mathrm{ha}$, with most of the accounts for the underground part (80-90\%) This ratio is characteristic for the vegetation of subalpine meadows and consistent with the environmental conditions of high mountains.

The rich grass vegetation with a well developed root system and relative softness compared to the alpine climate zone contribute to the development of loose sod horizon. This is one of the characteristic features of the morphological structure of mountain meadow sod soils.

In the subalpine zone basin of the rivers Garachai-Velvelichai is mainly mountainmeadow turf and mountain-meadow soil.

Mountain-meadow sod soils are typical soils of the subalpine belt. In the study area, they occupy a large area - 28255 ha.

Mountain-meadow sod soils developed under leaching regime, due to high atmospheric humidity and enough good drainage. The features of the morphological structure of mountain meadow sod soils are: a short profile; capacity of fine-earth layer is typically less than $60-70 \mathrm{~cm}$; sod layer on the surface of a capacity of $5-7 \mathrm{~cm}$. Compared with the mountain-meadow turfpeaty soils of the sod layer gives a little more density and friable. Mountain meadow sod soils are characterized by a clear differentiation profile on the horizon, welldefined and gravelly humus horizon of the entire profile.

Carbonate formation are not available in the profile, the mountain meadow sod soils is 
characterized by leaching of carbonates.

The humus content in the upper horizon mountain meadow sod soils of the study area is on average $4.35 \% \pm 0.47$; the average content of total nitrogen in the same horizon $0.32 \pm 0.02 \%$ and $0.33 \pm 0.02 \%$ phosphorus. Reserves of humus in the meter layer is $333.07 \mathrm{t} / \mathrm{ha}$. The humus is dominated by fulvic acids - $41-49 \%$ humic acids - 26-28\%. This soil is saturated sufficiently by exchangeable bases $-27,5 \pm 0.97 \mathrm{mEq} / 100 \mathrm{~g}$ of soil. In the humus horizon in the composition of exchange cautions is increased content of $\mathrm{Ca}$ and $\mathrm{Mg}$, which is caused by the accumulation of mineral elements.

The reaction of the soil solution is weakly acid or close to neutral ( $\mathrm{pH} \mathrm{6,2-6,7).}$

By particle size composition the mountainmeadow sod soils consist principally of light and medium loamy composition. Silt particles are not too much, their content in the upper layers does not exceed 7,38$10,08 \%$, physical clay content ranges from 28.28 to $53.20 \%$ in the upper horizons.

Mountain-meadow sod soils have sufficient feeding element reserves. Water-physical properties are also favorable as a result of aggregation of good humus horizon, high water capacity and water permeability. Among the unfavorable properties are negative thermal conditions in the colder periods of soil freezing at a certain depth.

The mountain-meadow humus-like soil. The lower altitudinal limit of their extension takes place at a height of 1800-2000 meters above sea level. The mountain-meadow humus soils are formed under leaching regime on the residual weathering crust of limestone, calcareous sandstones and calcareous shale. These soils are formed in a more mild forms of relief - aligned inclined surfaces, plateaus, intermountain depressions, etc.

The mountain-meadow humus soils occupy in the river basin area Garachai-Velvelichai area 10335 ha. In the study area mountainmeadow humus soils are confined to the intermountain depressions, aligned inclined surfaces and are found in small patches. Vegetation is represented by subalpine tall grasses with a significant participation of cereals. A well-developed herbaceous vegetation contributed to the formation of a powerful layer of sod. The mountainmeadow humus soil sod has a "steppe" nature compared to the mountain meadow sod soils, degree of sods is deeper, sod capacity reaches $15-20 \mathrm{~cm}$. The value of the total biomass of the territory for the spread of mountain-meadow humus-like soils averages $391-489 \mathrm{~kg} / \mathrm{ha}$, of which the aerial part accounts for only $41-49 \mathrm{~kg} / \mathrm{ha}$, and the rest - at a fraction of the roots.

The most characteristic diagnostic features of the morphological structure of mountain meadow humus soil: a clear differentiation of horizons, the presence of a dense sod, deep humus content, granular structure and fine- nuciform humus horizon, the severity of the illuvial horizon B. Carbonates are observed only in horizon $\mathrm{B} / \mathrm{C}$ or $\mathrm{C}$.

The humus content in the upper horizon mountain meadow is on average $4.95 \%$ $0.56 \%$; nitrogen content of $0.35 \%$ in this horizon $0.02 \%$. Humus reserves in the meter layer is $203.81 \mathrm{t} / \mathrm{ha}$. Absorption capacity of these soils is averaging $27.720 .89 \mathrm{mEq} / 100$ $\mathrm{g}$ of soil. Reaction of the soil solution is weakly acid to neutral or near - from 6.2 to 6.8 .

By particle size distribution of mountainmeadow humus soils are represented by medium- and heavy varieties. Number of 
physical clay in the upper horizons is within 35,86-60,82\%. Silt particles are depleted in the upper horizons: an average of no more than $9.6 \%$, with the depth of their number slightly increased (up 12.74\%), which may indicate a weak clayey mountain-meadow humus-like soils.

The mountain-meadow humus soils are highly productive and are included in the general fund of Azerbaijan lands for pasture and hay land. Some of them are plowed under crops and potatoes.

Sub-alpine meadows are used for summer pastures and hayfields. On the territory of the landscape take place erosion processes, although to a lesser extent than in the alpine meadows. The development of erosion processes influenced relief area. Territory of alpine meadows is characterized by complex geomorphologic structure and the significant vertical and horizontal unbundling. There is a dense valley-gully network of $3.5-5.0 \mathrm{~km} /$ $\mathrm{\kappa м}^{2}$. Within this landscape the slope surface reaches the $45^{\circ}$. Therefore, there are widespread forms of relief, formed as a result of gravitational processes: landslides, mudslides, landslides, causing a decrease in the area of mountain meadows.

Unsystematic and overgrazing and absence of proper care for the sub-alpine meadows, especially near villages, caused in recent years reduction of their productivity, deterioration of the species composition, decrease of cover, the emergence of erosion bed and the talus processes. Of the total area of subalpine meadows of the territory of 15,544 hectares or $40.28 \%$ are subject to erosion.

Development of pasture digression depends on the specific features of grazed animals, intensity and duration of the use of pastures, endurance pasture vegetation to trampling.
On the re-grazed grassland areas dominated by sedge and cobresial-sedge associations, in which are found badly eaten and poisonous plants (gentian, wrestler, buttercup, hellebore, and others.). So according to 40-year-old data (Hajiyev, 1974), the productivity of subalpine meadows was 285-349 kg/ha, of which 3256 tons/ha were in the aboveground biomass. According to our data, the productivity of subalpine meadows (aboveground biomass) in the study area is $30-42 \mathrm{~kg} / \mathrm{ha}$. The reduction amounts to an average of $18 \%$.

Under the influence of grazing soil properties significantly alter, especially their physical properties. Soil compaction occurs under the influence of the hooves of animals, which is associated with a decrease in porosity, especially inter-aggregate, and the deterioration of the water-air regime. Deteriorating soil structure, reduces water resistance units. For example, in a mountain meadow sod soils of the study area, where the rules have been complied with grazing water-resistant aggregates content is $71.8 \%$, soil density of $1.04 \mathrm{~g} \mathrm{/} \mathrm{cm3,} \mathrm{the} \mathrm{total}$ porosity of $55.3 \%$ and a permeability of 5.3 $\mathrm{mm} / \mathrm{min}$. When the rain in these soils is a gradual absorption of moisture and erosion processes are not observed. In uncontrolled grazing and higher than normal in these soils the content of water-stable aggregates was $53.4 \%$, soil density of $1.51 \mathrm{~g} / \mathrm{cm}^{3}$, the total porosity is $39.2 \%$, and a permeability is 0.5 $\mathrm{mm} / \mathrm{min}$ (Shabanov et al., 2015).

If we compare the data of previous years by chemical and physic-chemical properties, we will see noticeable differences. Currently, the humus reserves in the 0-50 $\mathrm{cm}$ layer of the mountain meadow sod soils in comparison with previous data is less than $31 \mathrm{t} / \mathrm{ha}$, or $25.5 \%$, and in the mountainmeadow humus soils - $26,8 \%$. 
To maintain soil subalpine meadows and improve productivity a number of reclamation and agro-technical measures for erosion prevention, compliance grazing, use of artificial grass cultivation and fertilizer is required.

Subalpine meadow steppe. Meadow steppe zone is located approximately at the same height where there are subalpine meadows (1900-2100 m), but they occupy a dry, welldrained, leveled plateaus.

Climatic conditions of the landscape are characterized by some features of aridity. The average annual temperature is slightly higher than in mesophilic subalpine meadows and is $8,5-11,10$. The average annual precipitation does not exceed 475 $550 \mathrm{~mm}$, dampening factor is $0,7-1,12$.

The vegetation is represented more by xerophytes grasses and forb cenosis. The main sod is formed by fescue, brome, savory. The average value of the aboveground biomass of the present time is $1,8 \mathrm{t} / \mathrm{ha}$, i.e. much lower than the soils of subalpine meadows. In these steppe cenoses decomposition of organic litter is more intense than in the subalpine meadows. Compared to previous data $(2,2 \mathrm{t} / \mathrm{ha})$, the average productivity decreased by $16 \%$.

Under such circumstances are formed mountain meadow-steppe soils - soil typical for subalpine meadow steppe. They occupy more dry areas of high mountains with a good drainage of the territory, and increased surface runoff associated with steep slopes and good permeability of the bedrock. In the basin of the rivers Garachai-Velvelichai the mountain meadow-steppe soils occupy 16886 hectares.

The mountain meadow-steppe soils by their morphological properties are similar to the mountain-meadow humus, but have some distinctive features. First of all, they differ by the degree of humus coloration, nature and depth of sods, and deep leached.

Morphological features of mountain meadow-steppe soils are characterized by lower genetic differentiation profile on the horizon, the presence of loose turf surface, dusty granular structure of the humus horizon, the lack of severity in the illuvial horizon, brown-brown color, the absence of carbonate formations.

The average humus content in these soils is

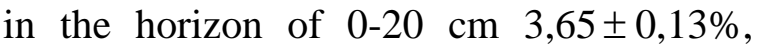
nitrogen $-0,30 \pm 0,01 \%$; the mean phosphorus content is $0,29 \pm 0,02 \%$; the amount of exchange bases on average is $29,15 \pm 0,90 \mathrm{mEq} / 100 \mathrm{~g}$ of soil. As part of the exchangeable bases Ca prevails.

The reaction of the soil solution close to neutral - 6,5-6,7.

By particle size content in the study area is marked by medium- and heavy difference, the amount of physical clay in the upper horizon varies from 37.88 to $56.52 \%$. The content of the clay fraction and its distribution over the profile indicates a small accumulation of these particles in the humus horizon $(9,16-10,28 \%$.) With the depth of movement the clay particles are not observed (8,40-11,20\% in the subsurface).

The mountain meadow-steppe soils are used as grasslands, and part of the main fund fodder lands of the country. Erosion processes they developed somewhat weaker than in the soil of alpine and sub-alpine meadows. Total erosion exposed to 2946 hectares, or $17.45 \%$, of which 1146 hectares are medium eroded, and 1801 hectares are weakly eroded. This is, probably, because the soil data is not longer used for grazing and for hay, respectively, there is no pasture 
digression development. However, to prevent further erosion and decrease the productivity of the landscape, it is necessary to carry out land improvement measures, in particular grass cultivation on disturbed areas, the application of mineral and organic fertilizers.

In conclusion, soil alpine ecosystems are a major array of highly productive summer pastures and hayfields. The ecological significance of these soils is not confined to the agricultural aspect, they play an important role in the hydrological regime of mountain areas. Soil alpine zone are subject to various types of degradation, the main cause of which is the development of erosion processes. First of all, the development of erosion highland ecosystems is associated with grazing. Unregulated grazing leads first to a change in plant formations (cereals and cereal-legume plants are replaced by weeds), thinness, and then the destruction of vegetation, which in turn leads to soil degradation, the so-called pasture digression. Therefore, their conservation should be strictly abide by grazing (no more than 5-8 small cattle per hectare), and where plant and soil cover is much disturbed, completely ban grazing for a certain time (2-3 years), and sow on areas turf plants, such as fescue, brome, bluegrass, cuff, etc. till full restoration of vegetation and soil cover.

\section{References}

Aliyev, G.A. 1978. The soils of the Great Caucasus. Part 1, Baku: Elm. 156 p.

Aliyev, G.A., Salamov, G.A. 1986. Soil and landscape modification of the natural environment in the mountain regions of Azerbaijan, and their evaluation // Environmental Issues of the Azerbaijan SSR. Baku: Elm, 4-10 p.

Babayev, M.R., Hasanov, V.G., Jafarov, Ch.M., Huseynova, S.M. 2011.
Morphogenetic diagnostics, nomenclature and classification of soils of Azerbaijan. Baku: Elm., 452 p.

Belozertseva, I.A., Dorzhgotov, D., Enhtayvan, D., Cherkashina, A.A. 2011. Rationing grazing loads and prediction of soil degradation and Hovsgol region // Compilation of the 2-nd International Conference "Diversity of soil and biota in North and Central Asia." Ulan-Ude, 10-12 p.

Budagov, B.A. 1988. Modern natural landscapes of the Azerbaijan SSR. Baku: Elm., 136 p.

Gunya, A.N. 2010. Landscape framework for the analysis of natural and naturalanthropogenic changes in mountainous areas. Nalchik Izd.KBNT. RAN., 199 p.

Hajiyev, V.D. 1974. The dynamics and productivity of plant formations of the highlands of the Greater Caucasus. Baku: Elm., 258 p.

Kohler, Th. and Maselli, D. (Ed.). 2012. Mountains and climate change. From understanding to action. Centre for Development and Environment (CDE), Institute of Geography, University of Bern. 3-rd edition, 80 p.

Mamedov, G.S. 2004. Ecoethical problems of Azerbaijan: the scientific, legal and ethical aspects. Baku: Elm, 378 p.

Mamedov, G.S., Mammadova, S.Z., Shabanov, J.A. 2009. Erosion and soil protection. Baku: Elm, 340 p.

Museibov, M.A. 2013. Landscapes of the Azerbaijan republic (spatial orientation and evolution). Baku: BSU, $152 \mathrm{p}$.

Salayev, M.E. 1991. Diagnosis and classification of soils of Azerbaijan. Baku: Elm, 240 p.

Shabanov, J.A., Kholina, T.A. 2015. Degradation highland ecosystems soil in the north-eastern slope of the Greater Caucasus and their protection 
// International scientific conference "The role of soils in the biosphere and human life" by the 100th anniversary of academician Dobrovolsky G.V. Moscow, 136-138 p.

Shihlinsky, E.M. 1969. The heat balance of the Azerbaijan SSR. Baku: Elm, 199p.

Torehanov, A.A., Smailov, K.S. 2005. Methods of use of pastures and their effects on soil fertility // Vestnik of Agri. Sci. Kazakhstan, 5: 11-13p.

Usmanov, R.Z. 2009. Environmental assessment and the scientific basis of restoration of degraded soils natural potential of the North-West Caspian: Dis. Kand. Biol. Sci., Makhachkala.
$270 \mathrm{p}$.

Vosgan, Z., Vidican, R., Jelea, S., Marian, M., Mihalescu, L., Mare, R. 2011. Characterization of a Typical Districambosol Soil from the Gutai Mountains - North of Romania // Bull. Univ. Agr. Sci. Vet. Med., ClujNapoca, 68(1): p. 384-387.

Willat, S.T., Pullar, D.M. 1984. Changes in soil physical properties under grazed pastures // Austral. J. Soil. Res., Vol.22, P.343-348.

Zucca, C., Canu, A., Previtali, F. 2010. Soil degradation by land use chac ge in an agropastoral area in Sardinia (Italy). Catena. Vol. 83 (1) 46-54.

\section{How to cite this article:}

Shabanov, J.A., and Kholina, T.A. 2016. Soil and Landscape Changes in the Alpine Zone Basin of the Rivers Garachay-Velvelechay. Int.J.Curr.Microbiol.App.Sci. 5(10): 1039-1048. doi: http://dx.doi.org/10.20546/ijcmas.2016.510.110 